\title{
PERANCANGAN GAME "YUK, SUKSES UN!" \\ SEBAGAI MEDIA PEMBELAJARAN PARA SISWA \\ DALAM PERANGKAT SMARTPHONE
}

\author{
Godham Eko Saputro \\ Dosen Jurusan Disain Komunikasi Visual \\ Fakultas Ilmu Komputer \\ Universitas Dian Nuswantoro, Semarang \\ E-mail: godham.eko@gmail.com
}

\begin{abstract}
Games are entertainment media with the highest growth among other smartphone features such as music, TV, and movies. Besides having a huge potential in the field of economic and entertainment, the game also has the potential field of instructional media. The students assume the National Examination as a fear factor can utilize the smartphone as a learning medium, especially students who come from rural areas who have difficulty in accessing the textbook exercises.

By utilizing the game functions as a medium of learning the game design \&quot;Yuk, UN Success!\&quot; In the android operating system which includes a question bank content package, a summary of the material, the lattice, and the discussion of the UN is expected to increase the graduation rate of students nationally
\end{abstract}

Keywords: Game, Medium oflearning, Android.

\section{Pendahuluan}

Ujian Nasional atau UN/ UNAS merupakan suatu program Pemerintah yang diadakan untuk menjadi tolak ukur kemampuan siswa dalam hal penyerapan proses belajar di pendidikan dasar dan menengah (Siswa SMA) SMK/ MA) selama 3 tahun bersekolah secara nasional. Meskipun UN sempat menjadi pro dan kontra, namun Kementrian Pendidikan dan Kebudayaan (sebelumnya Kementrian Pendidikan Nasional) tetap menyelenggarakan UN karena sudah diatur dalam Undang-undang Republik Indonesia nomor 20 tahun 2003 yang menyatakan bahwa dalam rangka pengendalian mutu pendidikan secara nasional dilakukan evaluasi sebagai bentuk akuntabilitas penyelenggara pendidikan kepada pihak-pihak yang berkepentingan(UURINo 20/2003)

Bagi sebagian siswa, UN merupakan momok yang menakutkan, menegangkan, dan sebuah mimpi buruk bagi siswa. Hall, C. S. (1954) dalam bukunya A primer of Freudian psychology

menjelaskan bahwa kecemasan dan ketakutan yang dialami siswa sebagai kecemasan objektif (Objective anxiety). Siswa yang merasa tidak siap akan terlihat cemas dalam menghadapi syarat penentu kelulusan siswa tersebut. Efek kecemasan objektif ditanggapi beberapa sekolah dengan menggelar acara doa bersama/ istighosah dan pemberian motivasi psikologis untuk memberi semangat menjelang berlangsungnya $U N$.

Selain persiapan mental, kesehatan, dan kemampuan otak agar dalam pelaksanaan UN sukses sesuai harapan, terdapat beberapa kendala lain yang dihadapi para siswa, antara lain sarana dan prasarana antar daerah yang masih tidak merata atau timpang, juga tingkat pendidikan dan ekonomi yang cenderung heterogen. Di satu sisi sebagian sekolah terletak di kota besar/ pusat perekonomian dengan sarana dan prasarana yang sangat lengkap dan nyaman seperti fasilitas ruang AC, LCD, les tambahan, dan internet. Ironisnya, di sisi yang lain seperti sekolah di daerah masih 
minim fasilitas, bahkan kekurangan tenaga guru atau pengajar. Sebagai negara majemuk, dirasa kurang tepat ketika di Indonesia harus mengukur standar kelulusan secara nasional dengan menyama-ratakan berbagai macam adat istiadat, budaya, dan karakter yang beranekaragam. Hal tersebut disikapi beberapa penerbit dengan menerbitkan buku-buku rangkuman materi, kisikisi, dan bank soal UN, yang dapat diperoleh di toko-toko buku terdekat.

Buku yang ditujukan untuk para siswa sebagai persiapan menghadapi UN tersebut berisi soal dan pembahasan UN serta paket-paket soal latihan untuk mata pelajaran Bahasa Indonesia, Bahasa Inggris, dan Matematika. Paket-paket soal latihan tersebut disajikan sebagai sarana latihan agar para siswa siap dalam menghadapi UN yang sesungguhnya. Berdasarkan hasil pengamatan, beberapa hal yang dirasa kurang dari buku tersebut adalah cara penyampaian informasi buku yang kaku, kurang komunikatif, serta kurangnya aspek inovasi, Visualisasi buku yang kurang menarik dan terkonsep, dan Harga buku yang kurang terjangkau, sedangkan tiap tahun selalu ada edisi baru soal (up to date).

Di sisi lain perkembangan teknologi informasi internet telah memberikan berbagai dampak positif bagi seluruh elemen masyarakat Indonesia khususnya para siswa yang akan menghadapi UN. Para siswa di daerah terpencil dapat dengan mudah mengakses informasi dunia pendidikan. Hal ini merupakan sebuah jawaban jitu untuk membuat dunia pendidikan Indonesia mempunyai standar yang sama di semua kota atau daerah karena akses informasi pendidikan melalui media internet tidak terkendala dengan jarak dan waktu. Para siswa atau Institusi pendidikan yang kurang jeli dalam memanfaatkan internet akan kalah bersaing. Berkat revolusi teknologi, internet tidak hanya dapat diakses dari komputer atau warnet, tetapi juga dapat diperoleh dari telepon cerdas atau biasa disebut smartphone yang berukuran kecil dan dapat dibawa kemana-mana.

Perangkat penunjang seperti smartphone menunjukkan peningkatan yang sangat signifikan dan sudah merambah ke berbagai pelosok tanah air karena harganya yang kian terjangkau kantong para siswa. Ini tentu berita yang menggembirakan karena informasi apapun akan cepat disebarkan ke berbagai penjuru tanpa menunggu waktu yang lama. Mengunduh aplikasi atau game dari smartphone sudah bukan hal asing bagi masyarakat Indonesia, apalagi dengan harga yang murah meriah atau bahkan gratis. Beberapa tahun lalu muncul anggapan bahwa musik adalah fitur utama sementara game dan TV hanya sebagai pelengkap saja.

Kini game dalam smartphone semakin canggih, maka bermain game pun semakin mudah dan praktis dimanapun berada. Kehadiran smartphone di seluruh penjuru Indonesia telah merevolusi gaya baru bermain game, apalagi semakin banyak jenis permainan yang dapat dikombinasikan dengan media pembelajaran (Educational games). Beberapa contoh game yang sukses dijadikan sebagai media pembelajaran antara lain; "Rancangan Permainan Othello Berbasis Android Menggunakan Algoritma Depth-First Search" karya Mauza Saputri Handayani, Dedy Arisandi, Opim Salim Sitompul. Game Othello pada smartphone berbasis Android ini dirancang menggunakan kecerdasan buatan sehingga dapat membantu mencari solusi pada permainan Othello tersebut. Game edukasi "Rancang Bangun Permainan Edukasi Matematika dan Fisika dengan Memanfaatkan Accelerometer dan Physics Engine Box2d pada Android" karya Putri Nikensasi, Imam 
Kuswardayan dan Dwi Sunaryono ini juga berupa game edukasi yang menyenangkan dan sangat bermanfaat dengan teknologi accelerometer supaya permainan lebih menarik.

Berdasarkan pemaparan di atas, diperlukan perancangan media pembelajaran berupa game yang efektif dan efisien untuk yang dapat dimanfaatkan sebagai alat bantu dalam belajar, dimana game dapat diartikan sebagai bentuk dari multimedia interaktif untuk memberikan pengajaran atau menambah pengetahuan kepada para siswa melalui suatu media yang unik, menarik, dan menghibur. Keunggulan dari multimedia interaktif yang menggabungkan media visual, suara, dan pemrograman ini adalah paket soal dan pembahasan UN akan terus di update secara berkala dan dapat diunduh gratis di layanan android market atau playstore. Target audience game ini selain para siswa yang akan mengikuti UN, juga pelajar adik kelas, guru, tentor bimbel, pengajar les, bahkan masyarakat umum.

\section{Uraian Penelitian}

\section{Tujuan}

Merancang sebuah game yang unik, menarik dan menghibur yang berisi tentang paket bank soal, rangkuman materi, kisi-kisi, pembahasan UN serta memiliki fungsi edukasi melalui berbagai elemen yang diangkat dalam game tersebut seperti tta cara permainan, cerita, karakter, dan desain background, yang ditujukan bagi pelajar SMA/SMK/MA usia 16-18 tahun.

\section{Masalah}

"Bagaimana merancang game dengan konten paket bank soal, rangkuman materi, kisikisi, serta pembahasan UN untuk meningkatkan angka kelulusan para siswa secara nasional?"

\section{Manfaat}

Dapat menjadi alat bantu untuk para siswa, guru/ pengajar, dan masyarakat umum dalam belajar, memberikan pengajaran/ menambah pengetahuan tentang paket bank soal, rangkuman materi, kisi-kisi, serta pembahasan UN melalui suatu media yang unik, menarik, dan menghibur tanpa terkendala oleh jarak dan waktu.

\section{Metode Perancangan}

Dalam pelaksanaan perancangan dibutuhkan beberapa jenis dan sumber data. Cara yang dilakukan adalah dengan studi pustaka dengan membaca literatur dan mempelajari tentang paket bank soal, rangkuman materi, kisikisi, pembahasan UN, panduan, modul serta segala kepustakaan lainnya yang dianggap perlu untuk lebih mempertajam konsep game yang akan dibuat. Wawancara dilakukan secara langsung terhadap para siswa, mengenai apa saja yang menjadi kendala, terutama dengan siswa dari daerah terpencil dalam memperoleh paket-paket soal latihan untuk menghadapi UN yang sesungguhnya. Teknik pengamatan dan analisis juga dilakukan untuk bertukar pendapat dengan para siswa, para guru pembimbing $\mathrm{UN}$, tentor lembaga bimbingan belajar seperti Primagama, Neutron, dan Ganesha Operation, guna mendapatkan informasi yang berkaitan dengan pokok bahasan.

\section{Landasan Teori}

\section{Game sebagai media pembelajaran}

Semua orang suka bermain dan tidak terbatas pada anak kecil saja karena bermain adalah sifat dasar manusia. Rieber (1996) berpendapat bahwa bermain, terutama pada anak usia dini, memainkan peranan penting dalam psikologi, perkembangan sosial dan intelektual, 
kegiatan sukarela yang secara intrinsik memotivasi, melibatkan beberapa tingkat aktivitas, dan sering memiliki kualitas terpercaya (Rieber, 1996: 43-58). John Huizinga, seorang profesor, teoritisi budaya dan sejarahwan Belanda menyebut manusia sebagai "makhluk bermain" atau Homo Ludens, makhluk yang suka bermain atau menciptakan permainan. Huizinga (gamestudies.org, 2006) mengemukakan bahwa bermain sebagai aktivitas yang bebas dan bermakna, dilakukan untuk manfaat permainan itu sendiri, terpisah dari syarat-syarat kehidupan pada prakteknya dan diikat oleh aturan-aturan tersendiri yang mengikat secara absolut (Hector, 2006).

Pada dasarnya sebuah game diciptakan bertujuan untuk menghibur. Saat ini hiburan merupakan salah satu kebutuhan penting bagi masyarakat untuk melepas jenuh, bosan, maupun penat. Salah satu cara yang digemari masyarakat untuk melepas jenuh, bosan, maupun penat adalah bermain aplikasi permainan yang populer dengan nama game atau video game. Kamus Merriamwebster mendefinisikan game sebagai aktivitas yang dilakukan untuk mengalihkan perhatian atau hiburan (Webster: 2008). Sedangkan Tracy Fullerton dalam bukunya Game Design Workshop (2008:43) mengungkapkan bahwa game merupakan suatu sistem formal yang tertutup, melibatkan pemain di dalam konflik yang terstruktur dan terdapat berbagai bentuk pemecahan masalah dengan hasil yang berbeda (Tracy: 2008)

Berikut ini beberapa alasan seseorang sangat menyukai game menurut studi beberapa ilmuwan di University of Essex (www.klikgame.com, 2011) Bermain game sangatlah menyenangkan, alasanya adalah cara terbaik menghabiskan waktu siang atau malam, dapat melakukan hal yang mustahil meskipun bukan sungguhan, dan perangkat yang sangat ideal bagi orang yang ingin mencoba karakteristik yang baru dan mencoba menjalani karakteristik yang mereka inginkan. Selain dampak positif, dampak negatif bermain game khususnya pada anak-anak baik itu pada perangkat komputer, konsol, atau pun berbagai perangkat smartphone tentu membuat banyak orang tua menjadi khawatir dan was-was. Sifat imersif game membuat pemain cenderung untuk kecanduan dan tidak sadar akan lingkungan sekitar, sehingga mempengaruhi moral dan tingkah lakunya dalam kehidupan sehari-hari. Tetapi kekhawatiran tersebut sebenarnya dapat dikesampingkan bila dibarengi dengan pengaturan waktu bermain serta pengawasan yang tepat.

Seiring dengan perkembangan jaman, jenis berbagai game dirancang untuk berbagai tujuan positif, seperti potensi meningkatkan minat belajar. Whelan (2005) mengemukakan bahwa belajar melalui media game dapat mengakuisisi pengetahuan baru, transfer pembelajaran, pengembangan keterampilan intelektual (abstraksi, antisipasi, pembangun strategi, pemecahan masalah, lateralisasi representasi, spasial, fungsi-gerakan hubungan), dan pengembangan perilaku dan sikap. (Whelan, 2005: 40-43) Randel (dalam Wiwik, 2009) mengemukakan bahwa game sangat berpotensi menumbuhkan kembali motivasi belajar anak yang mengalami penurunan. (http://medukasi.net)

Penelitian yang dilakukan oleh Randel mencatat bahwa pemakaian game sangat bermanfaat pada materi-materi yang berhubungan dengan matematika, fisika dan kemampuan berbahasa (seperti studi sosial, biologi dan logika). Sedangkan peneliti Lee, Luchini, Michael, Norris, dan Soloway (2004) mengemukakan bahwa game matematika untuk siswa kelas kedua pada 
perangkat gadget mendorong para siswa untuk menyelesaikan lebih banyak masalah pada tingkatan permainan. (Lee.at.al. 2004) Para siswa secara sukarela menyelesaikan hampir 3 kali jumlah masalah dalam waktu 19 hari. Hal tersebut menunjukkan bahwa game berhasil diterapkan untuk pendidikan formal dan proses belajar tampaknya berjalan lebih efektif.

\section{Berbagai elemen dalam game}

Game yang baik dapat menyeimbangkan antara elemen-elemennya, yaitu grafik, suara dan tata cara permainan. Berikut beberapa elemen yang terdapat dalam game yang akan digunakan dalam konsep "Yuk, Sukses UN!":

\section{Tata cara permainan (Gameplay)}

Tata cara permainan merupakan inti dan aspek yang paling menantang dari sebuah game. Tujuan utama disusunnya sebuah tata cara permainan dalam game ini adalah untuk mempermudah para siswa dalam mengoperasikan aplikasi dan mendapatkan berbagai umpan balik selama pengerjaan soal berlangsung. Sebuah tata cara permainan harus menarik, unik, orisinal, dan memiliki tiga kriteria, yaitu ditata dengan baik, menarik bagi pemain, dan tercapai tujuannya. Ketiga kriteria tersebut akan memancing para siswa untuk mencoba memainkan game, mereka tertarik untuk mencoba sebuah game dengan terlebih dahulu melihat tata cara permainannya.

\section{Antarmuka(Interface)}

Antarmuka adalah tampilan visual suatu layar dalam sebuah game. Para siswa melakukan input fisik melalui fitur layar sentuh (Touch screen) yang akan direspon oleh perangkat berupa output fisik. Dalam menu antarmuka terdapat beberapa pilihan (option) dan elemen atau obyek tombol sebagai alat navigasi. Menu antarmuka ini akan dirancang sedemikian rupa supaya memudahkan dalam permainan dan tidak membosankan.

\section{Sistem hadiah dan hukuman (Reward and punishment)}

Sistem hadiah dan hukuman, yaitu pemberian hadiah, penghargaan, atau bonus bila berhasil menyelesaikan soal, dan hukuman bila gagal tanpa sesuai instruksi. Beberapa jenis hadiah dalam game ini adalah score, tingkatan, dan kemenangan. Tentunya para siswa lebih menyukai hadiah daripada hukuman. Mereka berusaha menjawab soal latihan untuk mendapatkan score tertinggi dan akan menghindari mendapatkan score rendah.

\section{Aturan (Rules)}

Aturan adalah seperangkat pedoman yang sederhana atau kompleks, yang menggambarkan hubungan antara pemain dengan lingkungan permainan. Sedangkan Jenkins (2005) mengemukakan bahwa aturan merupakan kumpulan atribut yang penting dalam sebuah game. Aturan dalam game sudah dibuat dengan jelas dan secara otomatis pemain menyetujuinya sewaktu memainkan aplikasi tersebut.

\section{Tingkatan (level)}

Desain tingkatan menentukan faktor kesenangan dari pemain. Desain tingkatan akan mencakup semua gaya, latar belakang, dan penceritaan dalam sebuah game. Desain tingkatan dalam permainan ini memiliki karakteristik sendiri dalam setiap bagian dan tingkat kesulitan yang bervariasi, sehingga akan menambah pengalaman imersif pemain. Para siswa dapat melanjutkan permainan ketingkatan selanjutnya jika sudah menyelesaikan tingkatan sebelumnya. 


\section{Konsep visual}

Konsep visual merupakan segala sesuatu yang dapat dilihat oleh mata pemain. Aspek visual dapat berupa model grafik dua dimensi atau tiga dimensi. Grafik dua dimensi dibuat dengan garisgaris pada bidang, pewarnaan, gradasi dan efekefek percampuran warna. Grafik dua dimensi memiliki kesan tampilan lebih cerah, menarik, kasual, santai, dan dekat dengan para siswa yang sering mengkonsumsi objek bernuansa anime seperti komik, majalah, maupun animasi. Berdasarkan hal tersebut maka konsep visual yang akan diterapkan dalam game adalah model grafik dua dimensi

\section{Karakter}

Definisi karakter menurut kamus Merriam-Webster (2008) adalah atribut atau fitur yang memoles dan menandai seorang individu, suatu sifat mental dan etis yang rumit untuk menandai dan mengindividualkan seseorang, kelompok, atau negara. Dalam game ini karakter dan penokohan yaitu tokoh berusia remaja dan sedang menempuh pendidikan SMA yang memiliki penampilan, identitas, sifat, yang disesuaikan dengan target audience.

\section{Objek latar belakang (Background)}

Merupakan unsur-unsur, elemen-elemen, atau variabel-variabel yang mendukung sebuah game. Contoh objek latar belakang dalam game semisal benda-benda yang identik dengan keseharian anak SMA berupa lingkungan sekolah, atribut SMA, pensil, paket soal latihan, dan lainlain.

\section{Suara (Sound)}

Para siswa akan selalu dihadapkan dalam keadaan siap siaga karena dampak suara yang berfungsi sebagai aba-aba, peringatan, atau instruksi. Suara juga dapat membedakan identitas karakter yang sedang berbicara. Dengan hadirnya suara pada game akan membawa pesan dan informasi menjadi lebih sempurna dan menambah kualitas interaksi sebuah permainan.

\section{Sistem operasi Android}

Sistem operasi yang dipilih adalah android berbasis linux yang banyak digunakan oleh smartphone dan komputer tablet. Android menyediakan perangkat bagi para pengembang untuk menciptakan aplikasi gratis dengan kualitas cukup baik, mulai dari kategori game, aplikasi perkantoran, sosial media, chatting, dan hiburan. Awalnya, Google Inc. membeli Android Inc. yang merupakan pendatang baru untuk membuat software smartphone. Kemudian untuk mengembangkan Android, dibentuk Open Handset Alliance, konsorsium dari 34 perusahaan hardware, software dan telekomunikasi, termasuk Google, HTC, Intel, Motorola, Qalcomm, TMobile, dan Nvidia.

Pada saat perilisan perdana android, 5 November 2007, Android bersama Open Handset Aylliance menyatakan mendukung pengembangan open source pada perangkat mobile. Di lain pihak, Google merilis kode-kode android dibawah lisensi apache, sebuah lisensi software dan open platform perangkat selular. Kini android menjadi pesaing utama dari Apple dan banyak dipakai para pengembang untuk membuat aplikasi dan game.

\section{Mekanisme permainan}

Setelah mendaftar dan mendapatkan akun, para siswa dapat mengakses penuh game "Yuk, Sukses UN!" yang berisi materi soal UN beserta Pembahasan dan kisi-kisinya. Para siswa 


\section{Hasil Dan Pembahasan}

\section{Alur Penentuan Konsep}

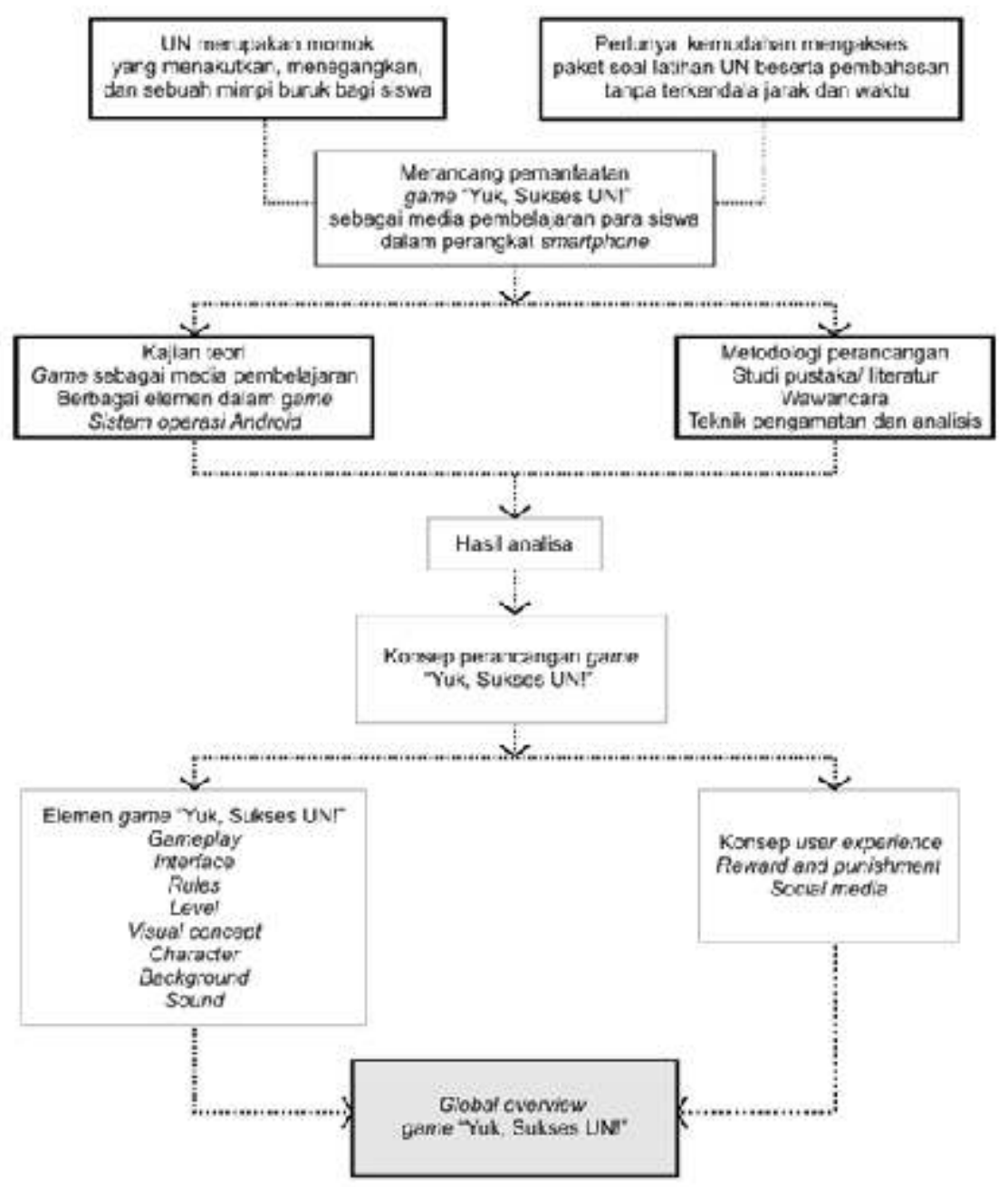

\section{Spesifikasi Teknis}

Judul Game : Yuk, Sukses UN!

Jenis/genre :Education game/Social media

Kategori :Mobile Application

Platform :Android(minimal versi 2.0) 4, 5, 7, dan 10 inch

Teknologi : Layar sentuh/Touch screen

Cara unduh : Gratis via playstore, android market

juga dapat memberi apresiasi dengan menekan icon 'Like', memberi pendapat lewat icon 'Komentar', dan membaginya ke jejaring sosial dengan menekan icon 'Share' sehingga dapat dilihat di wall/ dinding Facebook, harapannya adalah banyak menjaring siswa lain dan berbondong-bondong mengakses game ini. 


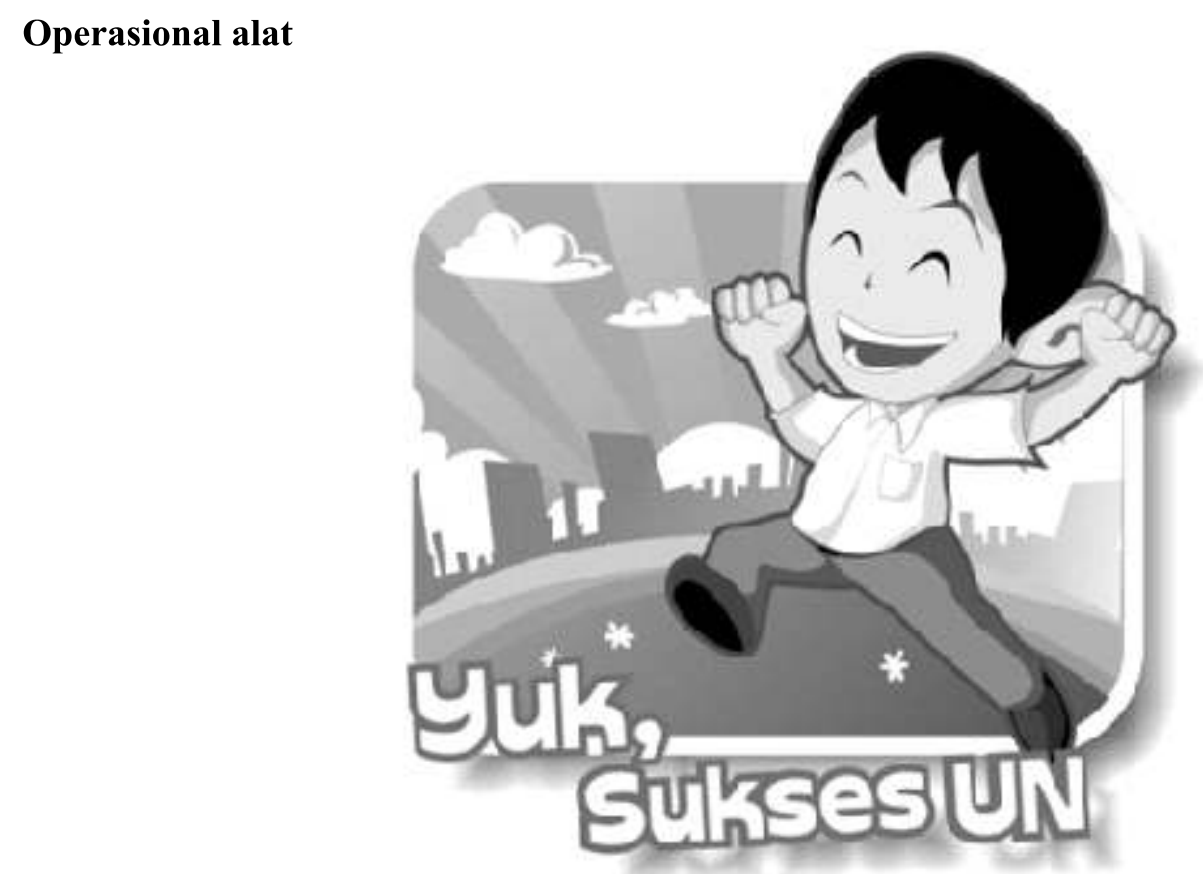

Logo game "Yuk, Sukses UN!"

Berbagai icon menarik dalam game "Yuk, Sukses UN!"

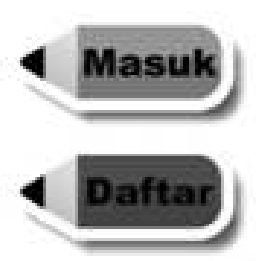

Icon untuk memulai

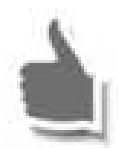
Icon untuk
menyukai

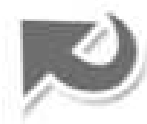

Icon untuk kembali ke menu sebelumnya

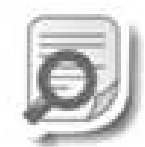

Icon untuk pembahasan

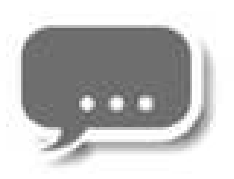

Icon untuk berkomentar/ berpendapat

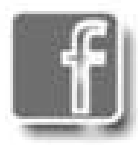

Icon untuk berbagi via Facebcok 


\section{Menu pembuka dalam game}

Berisi logo dan judul game, disertai tagline "See. Do it. And Share it" yang berarti Lihat. Kerjakan dan Bagikan.

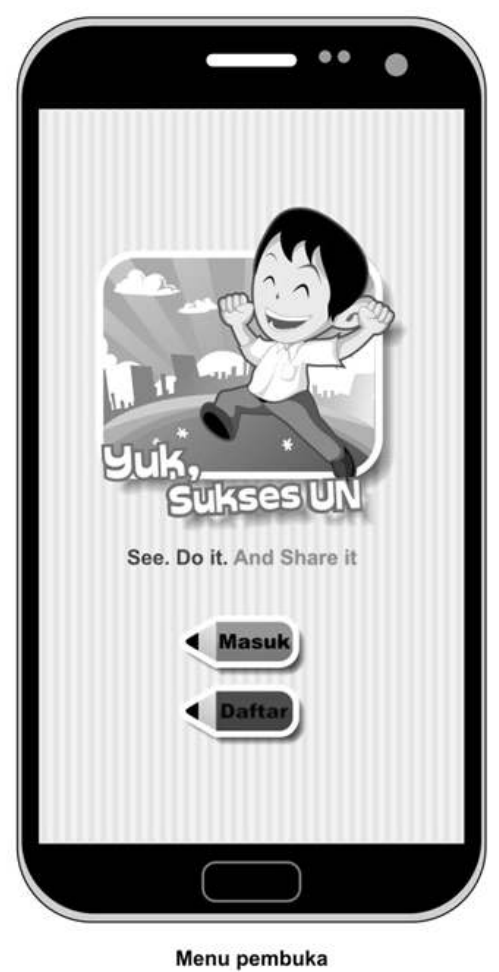

\section{Menu utama/ masuk/ sign in dalam game}

Menu ini diperuntukkan bagi para siswa yang sudah mendaftar, berisi perintah untuk memasukkan alamat email dan password, tekan tombol 'Masuk' untuk melanjutkan.

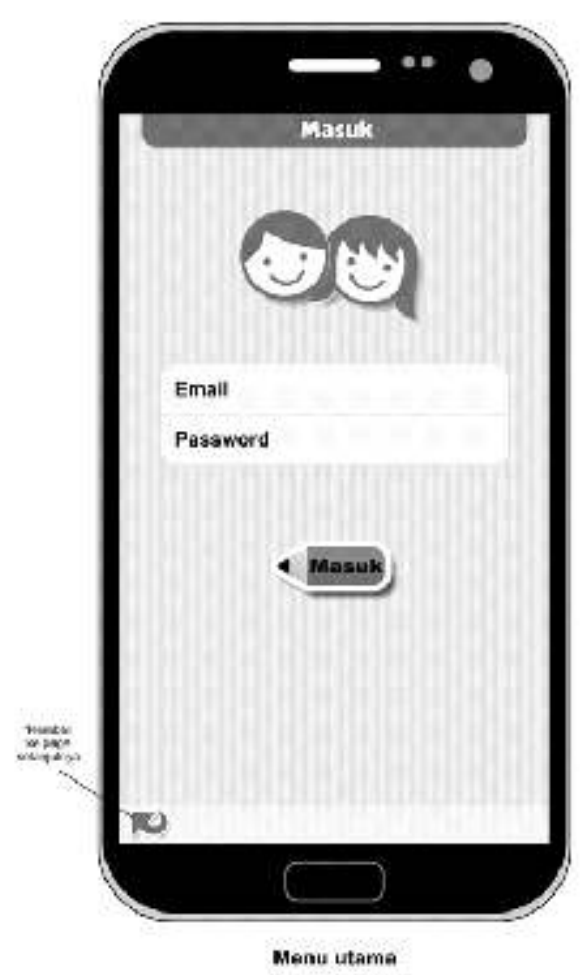




\section{Menu utama/ pendaftaran akun/sign up dalam game}

Menu ini diperuntukkan bagi para siswa yang belum mendaftar, silahkan mendaftar dengan mengisi alamat email, nama, password, dan foto pemilik akun. Tekan tombol 'Masuk' untuk melanjutkan

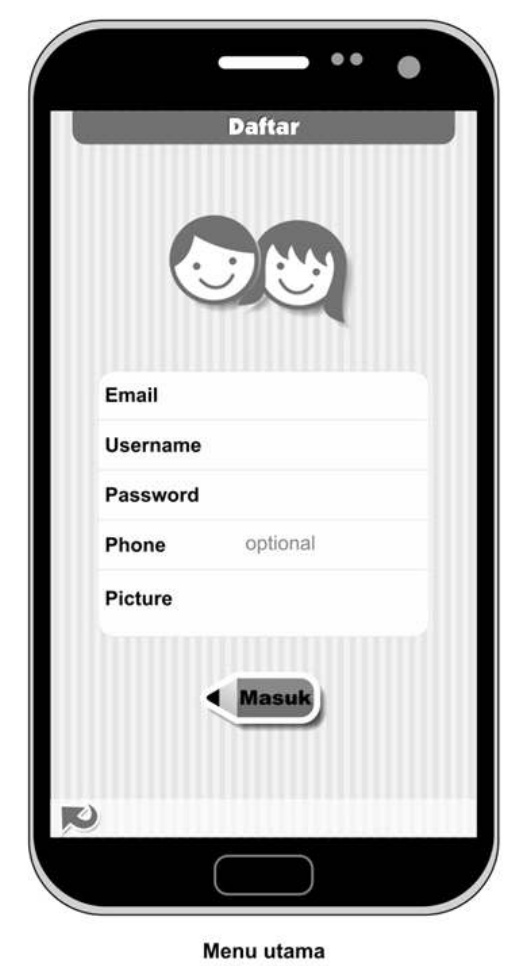

\section{Menu tampilan pilihan soal mata pelajaran}

Pengguna memilih soal mata pelajaran yang akan dikerjakan, tekan tombol mulai untuk mengerjakan, karena terdapat beberapa mata pelajaran, gunakan "Scroll" dengan menyentuh layar menggunakan jari untuk naik turun menyesuaikan jumlah mata pelajaran.

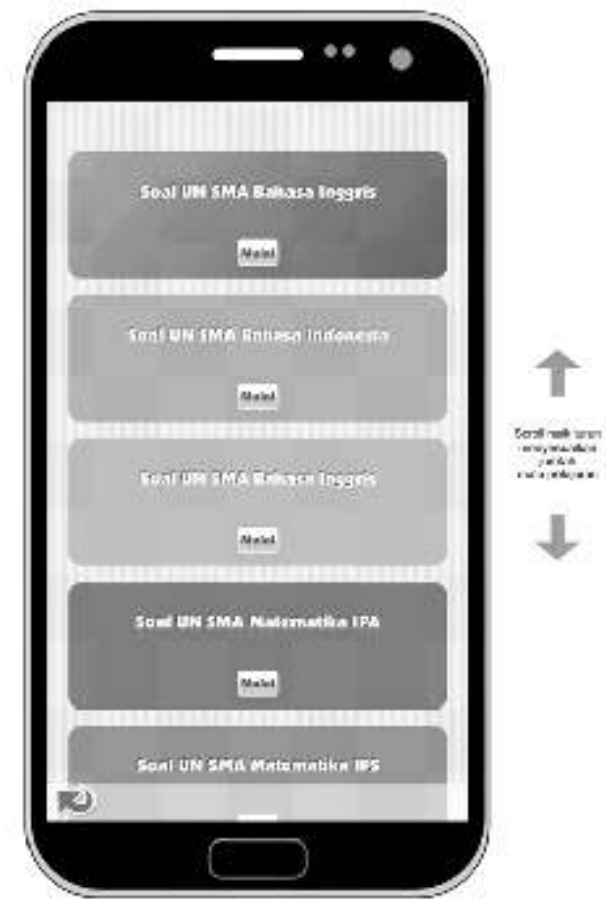

Menu tampilan Plihan soal mapal UN 


\section{Menu soal UN matematika IPS}

Salah satu menu pelajaran dalam soal game UN, khusus untuk mapel matematika IPS terdapat 40 soal. Gunakan 'Scroll' kebawah untuk mencari soal yang lain.

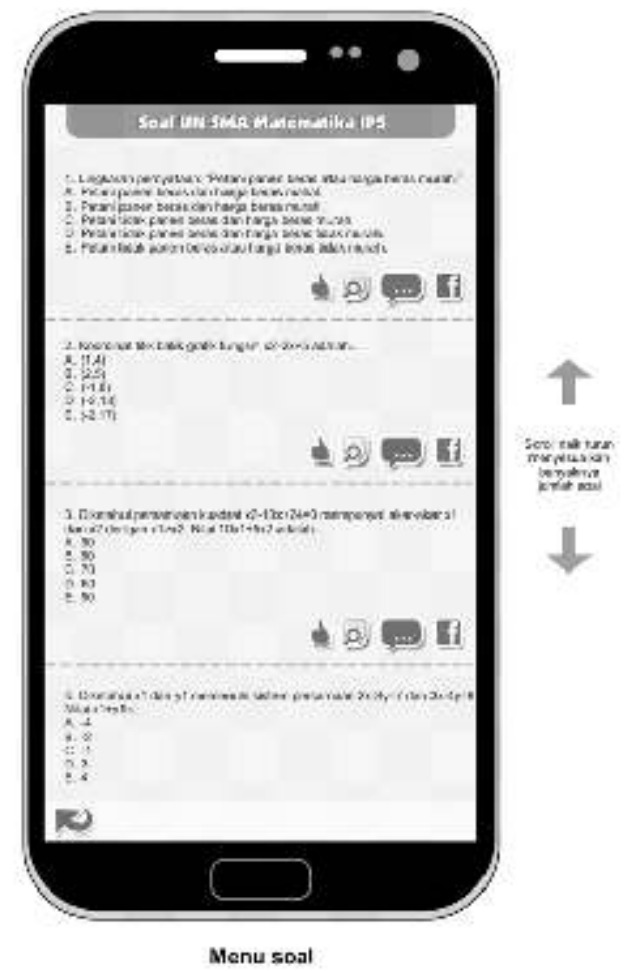

\section{Menu memilih jawaban dengan menyentuh pilihan huruf}

Sentuhlah menggunakan jari untuk memilih jawaban pilihan ganda, terdapat icon Jempol untuk 'nge-like' atau menyukai, icon kaca pembesar untuk menu pembahasan soal, icon balon kata untuk berkomentar, dan iconfacebook untuk berbagi via facebook.

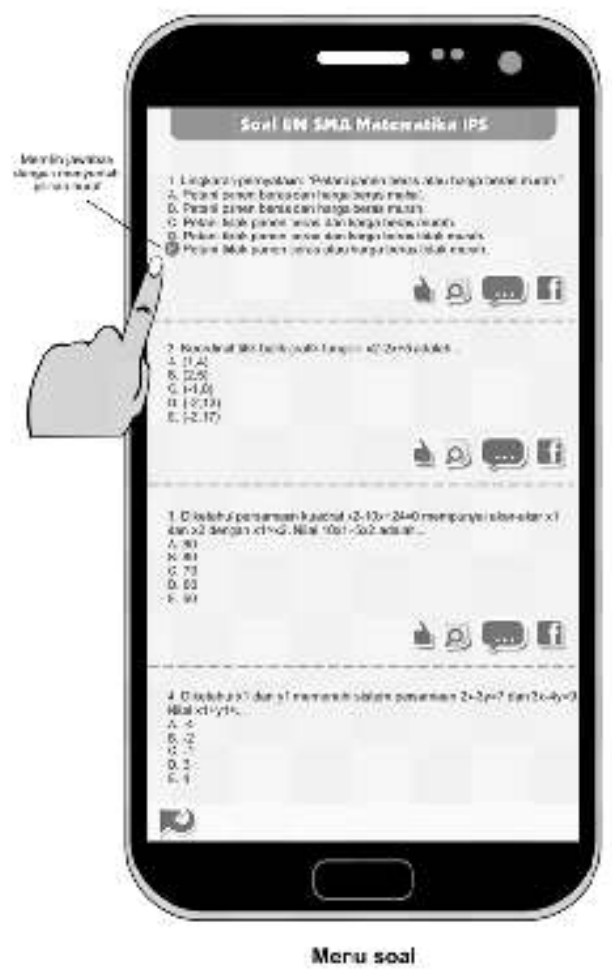




\section{Menu kunci jawaban}

Ketika semua soal sudah dikerjakan, maka akan muncul kunci jawaban yang otomatis akan menjumlah total score secara keseluruhan. Score baik atau buruk dapat di share/ dibagi viafacebook.

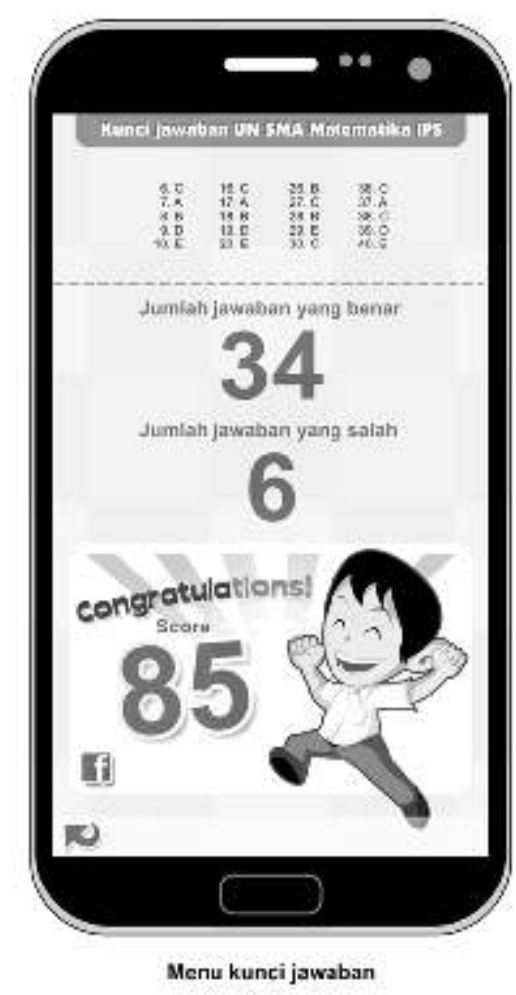

\section{Menu pembahasan soal}

Berisi penjelasan lengkap dan terstruktur dari jawaban soal UN, sehingga para siswa akan lebih memahami soal yang dikerjakan.

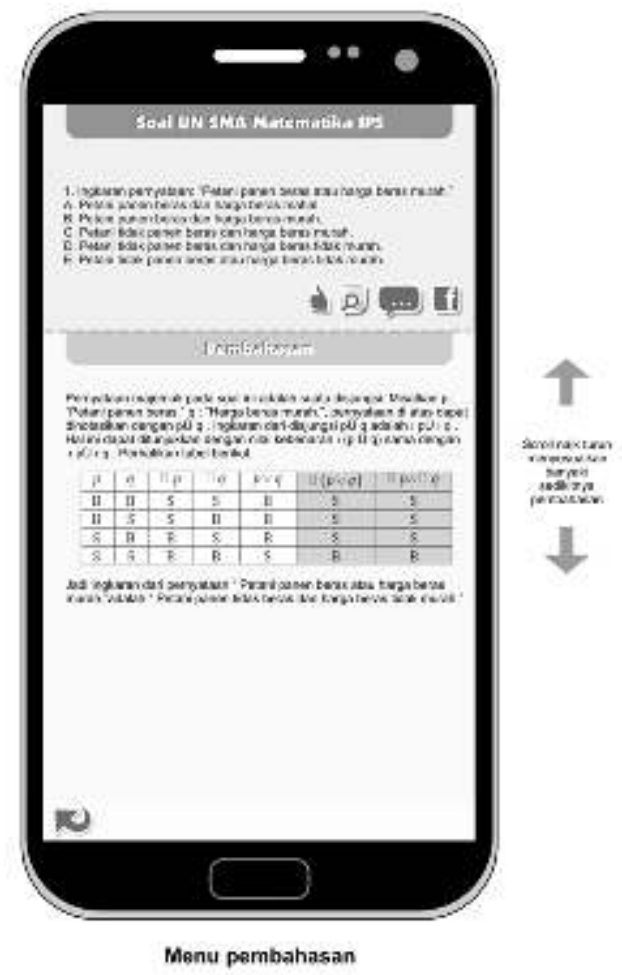




\section{Menu komentar para siswa/ users}

Menu ini berisi kicauan atau komentar para siswa yang saling berinteraksi satu sama lain sehingga layaknya jejaring sosial facebook atau twitter.

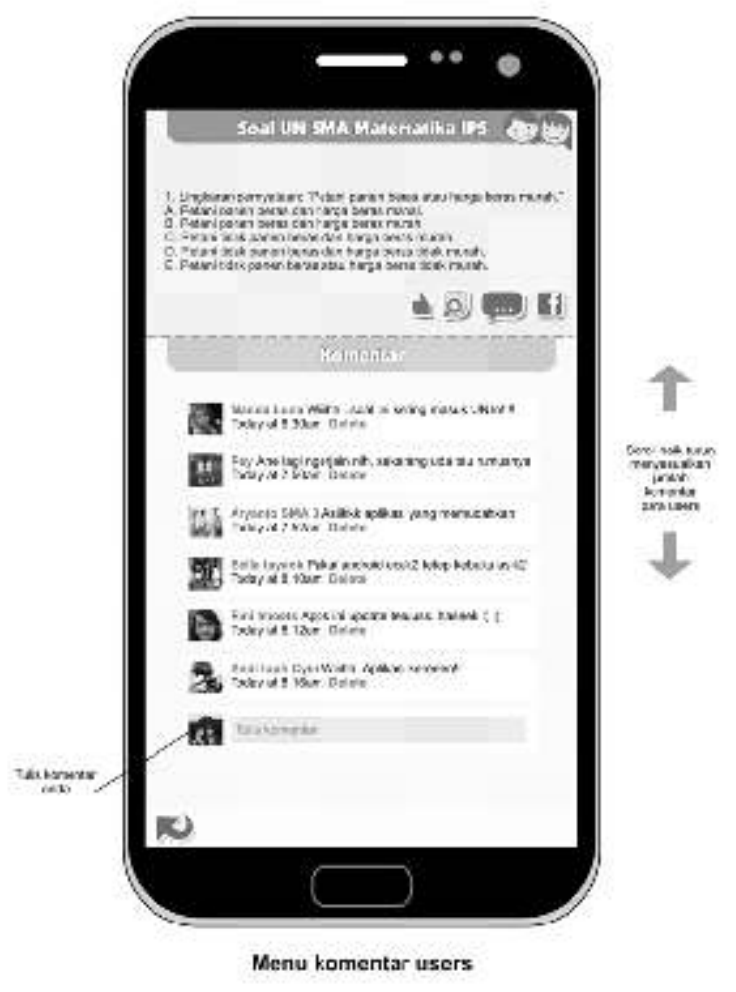

Keunggulan game "Yuk, Sukses UN!" ini antara:

Gratis, mudah di unduh, tidak perlu via laptop/ komputer/ warnet, tetapi langsung lewat smartphone android, Simulasi permainan yang didesain semenarik mungkin, sehingga menciptakan suasana belajar serasa bermain, media yang dipakai adalah smartphone yang memang dekat dengan para siswa, dapat dibawa kemana-mana, dapat dimainkan setiap saat dimana saja, Soal mengacu pada kisi-kisi UN, disertai pembahasan yang lengkap, Kesamaan mutu dalam materi soal UN, Soal selalu rutin di update oleh tim pembuat soal, Tim pembuat soal adalah para guru yang kompeten di bidangnya, Terdapat menu "komentar para users" yang berisi kicauan para siswa yang saling berinteraksi satu sama lain sehingga layaknya jejaring sosial facebook atau twitter, dan Para siswa dapat membaginya ke jejaring sosial/ dinding facebook, sehingga dapat menjaring siswa lain dan berbondong-bondong mengakses game ini.

\section{Kesimpulan}

Pendekatan pembelajaran melalui game "Yuk, Sukses UN!" akan sangat tepat diterapkan untuk masyarakat khususnya para siswa. Ketika para siswa (terutama siswa dari daerah/ pedalaman) terkendala ruang dan waktu dalam mengakses buku konvensional, maka teknologi informasi lewat game "Yuk, Sukses UN!" adalah jawaban yang tepat dan ideal. Selain itu siswa yang belum memahami materi soal dapat mengulang materi tersebut sama persis dengan yang pernah di bahas sebelumnya, karena terdapat mode putar ulang atau replay. Penerapan game pada masyarakat ini juga akan dijadikan sebagai bahan acuan dan pengembangan dalam bidang pendidikan secara umum dan khusus.

Dengan memperhatikan perancangan 
yang telah dibuat, maka prospek pengembangan dapat dikembangkan lagi secara lebih luas, sebagai berikut: Akan sangat menarik jika game "Yuk, Sukses UN!" dibuat versi yang lebih kompleks lagi, dengan pengembangan narasi, tokoh, animasi, audio, tingkat kesulitan, dan tata cara permainan yang dibuat lebih inovatif. Game ini dilibatkan dalam event-event pelajar yang dipelopori oleh Kementrian Pendidikan dan Kebudayaan. Program game ini akan efektif jika semua pihak terkait secara sinergis dapat bekerjasama, juga mendapat sokongan dari Kementrian Pendidikan dan Kebudayaan, atau lembaga terkait pendidikan seperti Primagama, Neutron, atau Ganesha Operation.

\section{Daftar Pustaka}

Undang-undang Republik Indonesia Nomor 20 tahun 2003 Tentang Sistem Pendidikan Nasional.

Fullerton, Tracy. (2008). Game design workshop. USA: Elsevier Inc.

Hall, C. S. (1954). A primer of Freudian psychology. Cleveland: World.

Handayani, M., Arisandi, D., Sitompul, O. (2012). Rancangan Permainan Othello Berbasis Android Menggunakan Algoritma DepthFirst Search. Artikel Laman, jurnal.usu.ac.id/index.php/duniait/article/ view/411 (Diunduh: 25 Desember 2013)

Jenkins, Henry. (2005). Getting Into the Game. A r t i k e $1 \quad$ L a m a $\mathrm{n}$, http://mgicollaboration.pbworks.com/f/J enkins-GettingIntotheGame.pdf. (Diunduh 22 November 2012).

Lee, J., Luchini, K., Michael, B., Norris, C., Soloway, E. (2004) More than just a Fun and Games, Assesing the Value of Educational Video Games in the Classroom. Paper presented at the $\mathrm{CHI}$ '04 Extended Abstract on Human Factors in Computing Systems, Vienna, Austria.

Merriam-Webster. (2008). Merriam-Webster's Collegiate Dictionary, 11th Edition. USA: Merriam Webster Mass Market.
Rieber L P. (1996) Seriously considering play: Designing interactive learning environments based on the blending of microworlds, simulations, and game Educational Technology, Research, adn development.

Rodriguez, Hector. (2006). The Playful and the Serious: An approximation to Huizinga's Homo Ludens, Artikel Laman, http://gamestudies.org/0601/articles/rodr iges (Diunduh: 3 Oktober 2012)

Vincent. (2011). Riset: Alasan Kenapa Gamer Suka Main Game, Artikel Laman, http://www.klikgame.com/article/risetalasan-kenapa-gamer-suka-main-game (Diunduh: 4 November 2011).

Whelan, D. L. (2005). Let the Games Begin! School Library Journal

Wiwik akhirul aeni, M.Kom. (2009). Antara Game, Pendidikan dan HP (Game Mobile Learning Sebagai Wacana Pendidikan), A rtikel Laman, http:// medukasi.net/artikel-mobile-learningisi.php?kodenya=2009-ac (Diunduh: 29 November 2012) 